\title{
Service Business \\ How to boost frontline employee service recovery performance: The role of cultural intelligence \\ --Manuscript Draft--
}

\begin{tabular}{|c|c|c|}
\hline Manuscript Number: & \multicolumn{2}{|l|}{ SBUS-D-17-00233R2 } \\
\hline Full Title: & \multicolumn{2}{|c|}{$\begin{array}{l}\text { How to boost frontline employee service recovery performance: The role of cultural } \\
\text { intelligence }\end{array}$} \\
\hline Article Type: & \multicolumn{2}{|l|}{ Empirical article } \\
\hline Corresponding Author: & \multicolumn{2}{|l|}{$\begin{array}{l}\text { Annelies Costers } \\
\text { Katholieke Universiteit Leuven } \\
\text { BELGIUM }\end{array}$} \\
\hline \multicolumn{3}{|l|}{$\begin{array}{l}\text { Corresponding Author Secondary } \\
\text { Information: }\end{array}$} \\
\hline Corresponding Author's Institution: & \multicolumn{2}{|l|}{ Katholieke Universiteit Leuven } \\
\hline \multicolumn{3}{|l|}{$\begin{array}{l}\text { Corresponding Author's Secondary } \\
\text { Institution: }\end{array}$} \\
\hline First Author: & \multicolumn{2}{|l|}{ Annelies Costers } \\
\hline \multicolumn{3}{|l|}{ First Author Secondary Information: } \\
\hline \multirow[t]{3}{*}{ Order of Authors: } & \multicolumn{2}{|l|}{ Annelies Costers } \\
\hline & \multicolumn{2}{|l|}{ Yves Van Vaerenbergh } \\
\hline & \multicolumn{2}{|l|}{ Anja Van den Broeck } \\
\hline \multicolumn{3}{|c|}{ Order of Authors Secondary Information: } \\
\hline Funding Information: & $\begin{array}{l}\text { Research Foundation - Flanders (FWO) } \\
(1 \mathrm{~S} 15155616 \mathrm{~N})\end{array}$ & Mrs Annelies Costers \\
\hline Abstract: & \multicolumn{2}{|c|}{$\begin{array}{l}\text { Satisfying complaining customers is challenging, especially when dealing with the } \\
\text { increasing number of customers with culturally diverse backgrounds. The purpose of } \\
\text { this study is to show whether and how frontline employee cultural intelligence (CQ) is } \\
\text { related to their service recovery performance. The results of among } 155 \text { flight } \\
\text { attendants of a Southeast Asian airline indicate that frontline employee CQ is positively } \\
\text { associated with their service recovery performance. Work engagement mediates this } \\
\text { relationship. This study reveals that organizations likely benefit from investing in } \\
\text { frontline employees' CQ to optimize their work engagement and service recovery } \\
\text { performance. }\end{array}$} \\
\hline Response to Reviewers: & $\begin{array}{l}\text { REVISION NOTES FROM THE AUTHC } \\
\text { Response to the reviewers } \\
\text { Thank you for the time you took to read a } \\
\text { checked the manuscript once again in orc } \\
\text { throughout the paper. } \\
\text { Sincerely yours, } \\
\text { The authors }\end{array}$ & $\begin{array}{l}\text { RS } \\
\text { review the manuscript. We double- }\end{array}$ \\
\hline
\end{tabular}


How to boost frontline employee service recovery performance:

The role of cultural intelligence

\author{
Annelies Costers \\ Yves Van Vaerenbergh \\ Anja Van den Broeck \\ KU Leuven, Belgium
}

Acknowledgement

The research for this paper was financially supported by an SB Fellowship of the Research Foundation - Flanders (FWO): 1S53218N.

Annelies Costers

annelies.costers@kuleuven.be

$+3223002212$

Yves Van Vaerenbergh

yves.vanvaerenbergh@kuleuven.be

Anja Van den Broeck

anja.vandenbroeck@kuleuven.be 


\begin{abstract}
Satisfying complaining customers is challenging, especially when dealing with the increasing number of customers with culturally diverse backgrounds. The purpose of this study is to show whether and how frontline employee cultural intelligence (CQ) is related to their service recovery performance. The results of among 155 flight attendants of a Southeast Asian airline indicate that frontline employee CQ is positively associated with their service recovery performance. Work engagement mediates this relationship. This study reveals that organizations likely benefit from investing in frontline employees' CQ to optimize their work engagement and service recovery performance.
\end{abstract}

Keywords: Cultural intelligence, Work Engagement, Service Recovery Performance 


\section{How to boost frontline employee service recovery performance: \\ The role of cultural intelligence}

\section{Introduction}

International trade and tourism are on the rise due to a number of factors, such as worldwide market liberalization, fewer travel restrictions, and openness to other cultures (Kotabe and Kothari 2016). Frontline employees working in the hotel and travel industry are therefore increasingly confronted with customers with diverse cultural backgrounds. How customers and employees perceive 'regular' intercultural service encounters has been relatively well-documented (e.g. Rizal et al. 2016; Sharma et al. 2009, 2012; Wang and Mattila 2010). Unfortunately, not every service encounter is successful. Service failures can cause significant customer dissatisfaction which requires frontline employees to engage in service recovery.

Research examining service recovery encounters between customers and employees predominantly take a customer perspective, seeking to understand how customers react to the organizational responses to complaints (see Table 1). Customers perceive a service recovery as satisfactory if the employee dealing with the complaint resolves the problem effectively within a reasonable period of time, offers compensation, listens carefully to the complaining customer, offers explanations, shows empathy, or allows the customer to participate in the recovery, among others (Gelbrich and Roschk 2011, Hazée et al. 2017, Liao 2007). Current studies examining customer reactions to service recovery in an intercultural context provide more nuance to these findings. They show that customers with different cultural backgrounds attach different value to recovery options like compensation, the status of the frontline employee who offers an apology, or an explanation depending on their cultural background (e.g. Hui and Au 2001; Orsingher et al. 2010; Patterson et al. 2006; Sengupta et al. 2018). Recovering from a service failure occurring in an interaction among customers and frontline 
employees who do not share the same cultural background thus adds a significant layer of complexity in service recovery performance.

\section{Table 1 here.}

How organizations can manage frontline employees' service recovery performance in an intercultural service recovery encounter is understood less clearly. The current literature taking an employee perspective to service recovery focuses exclusively on interactions between frontline employees and customers sharing the same cultural background. This research shows that frontline employees' service recovery performance is associated primarily with training, empowerment, or rewards for good customer service (Van Vaerenbergh and Orsingher 2016). We contend that focusing only on these job resources may be insufficient to fully understand frontline employees' recovery performance in intercultural service recovery encounters. As may become evident from the research on service recovery from a customer perspective, frontline employees who are increasingly confronted with customers with a different cultural background need to uncover these customers' expectations in order to provide a satisfactory service recovery.

Using the Job Demands Resources (JD-R) theory as a theoretical anchor (Bakker and Demerouti 2007; Bakker et al. 2014), the purpose of this paper is to address this apparent shortcoming in literature by examining whether frontline employees' cultural intelligence (CQ) serves as a valuable personal resource that is positively related to their recovery performance. CQ refers to an individual's ability to manage culturally diverse settings effectively (Ang et al. 2007). We therefore contend that frontline employees may benefit from being culturally intelligent in providing successful service recovery.

Specifically, this paper offers two main contributions to the service recovery literature. First, prior research focused mainly on understanding customer reactions to intercultural service recovery encounters, with little emphasis on the role of frontline employees. By 
examining whether CQ, as a personal resource, affects frontline employees' service recovery performance, we seek to provide support for Van Vaerenbergh and Orsingher's (2016) assertion that research may consider the role of frontline employees' personal resources (like CQ) in service recovery situations. In order to demonstrate the added value of CQ's relationship with service recovery performance, we will also examine whether CQ is related to service recovery performance above and beyond more established drivers of service recovery performance, that is training, empowerment and rewards (Van Vaerenbergh and Orsingher 2016).

Second, using the Job Demands-Resources theory as theoretical anchor, this research suggests that CQ relates to service recovery performance through work engagement. By proposing and testing work engagement as a mediator, we address Ott and Michailova's (2016) concern that "theory-based explanations for why CQ should be expected to increase [...] performance or other outcomes remain very slim" (p. 7). This study offers a theoretical account of how CQ relates to service recovery performance.

To examine the role of CQ on service recovery mediated by engagement, we report the results of a survey among a sample of flight attendants of a Southeast Asian airline. The results reveal that CQ forms a viable personal resource for frontline employees' service recovery performance in a culturally diverse context. Moreover, the results support an indirect effect of CQ on service recovery performance through work engagement.

These findings offer managers additional insights in how to manage their frontline employees for completing intercultural service recovery encounters effectively. Even though practitioners realize they cannot use a one-size-fits-all approach anymore when designing service recovery in a globalizing landscape (Accenture 2008), many organizations are still struggling with providing satisfactory service recovery. This study thus demonstrates how 
frontline employees' service recovery performance in an intercultural service encounter can be managed, using CQ as a personal resource.

\section{Literature review}

\subsection{Employees' service recovery performance and personal resources}

The goal of service recovery is to turn dissatisfied customers into loyal ones by resolving the problem resulting from a previous service encounter (e.g. Gelbrich and Roschk 2011). Service recovery requires a complex set of processes at different levels of the organization. On the one hand firms need to develop service recovery systems which for example formalize the recovery process, provide guidelines to employees, and develop a range of solutions that are both practical, possible, and fair to customers (Smith et al. 2009). On the other hand, firms also need to manage their frontline employees, as these typically play a boundaryspanning role between the organization and the complaining customer (Van Vaerenbergh and Orsingher 2016). After all, frontline employees are the ones who need to provide proper solutions to the complaining customers that fit within the boundaries of the organization's recovery system. Moreover, they need to solve customers' problems by showing empathy and handling the venting of customers' dissatisfaction well, and by providing explanations for the inconveniences of the customers, among others (Gelbrich and Roschk 2011; Liao 2007).

Against this backdrop, researchers started to examine how firms can manage frontline employees' service recovery performance, which refers to the effectiveness of employees dealing with customer complaints to the satisfaction of customers (Boshoff and Allen 2000). To date, research in service recovery offers insights on various job-related antecedents of service recovery performance, such as job demands (e.g. role ambiguity, role overload) and job resources (e.g. level of training, rewards, coworker support; Ashill and Rod 2011; Boshoff and Allen 2000; Kim and Oh 2012). Important to note, however, is that frontline 
employees' service recovery performance is not only influenced by their job-specific demands and resources, but they also bring their own, personal resources to the table (Van Vaerenbergh and Orsingher 2016).

Previous studies indeed show that personal resources, as part of the JD-R theory, can be important determinants of how employees perform in a work environment (Hobfoll 1989; Judge et al. 1997). The JD-R theory divides characteristics of the work environment into job demands and job resources, which evoke a health impairment process and the motivational process respectively (Bakker and Demerouti 2007; Van den Broeck et al. 2013). On the one hand, the health impairment process indicates that job demands drain energy and result in exhaustion, which is the core of burnout. On the other hand, the motivational process entails that the availability of job resources increases work engagement and other motivational outcomes such as organizational commitment (Schaufeli and Bakker 2004). More recently, personal resources were added to the JD-R theory (Xanthopoulou et al. 2007). Personal resources are defined as self-evaluations referring to individuals' sense of their ability to successfully control and impact their environment (Hobfoll et al. 2003). They are linked to resilience, are positively related to physical and emotional well-being (Scheier and Carver 1992) and have a positive impact on performance (Salanova et al. 2005; Xanthopoulou et al. 2007). Previous research in the realm of customer service examined personal resources such as customer orientation (e.g. Choi et al. 2014) or emotional intelligence (e.g. Lee et al. 2013), yet these studies did not take into account differences in cultural backgrounds between employees and customers.

\subsection{Cultural intelligence}

Customers with different cultural backgrounds have different expectations about a satisfactory service recovery (Orsingher et al. 2010; Patterson et al. 2006). Therefore, 
employees must have the necessary knowledge to properly assess what customers expect following a service failure. We advance that frontline employees' cultural intelligence (CQ) facilitates this process. CQ is a multidimensional construct including people's knowledge about cultures, the behavioral enactment of this knowledge, the ability to regulate their energy for a specific task or situation in cultural situations, and the processes to gain and understand this cultural knowledge (Ang et al. 2007). CQ can be conceptualized as a personal resource, as it is an aspect of the self that refers to an individual's sense of their ability to successfully adapt to their culturally different environment and is linked to resilience (Ang et al. 2007; Lin et al. 2012). CQ is also ductile and can be developed over time (Ng et al. 2012). The construct of cultural intelligence was developed by Ang and colleagues (e.g. Earley and Ang 2003) based upon theories of intelligence (Sternberg and Detterman 1986). Specifically, they designed a four-dimensional CQ framework that builds on the integration of a persons' various loci of intelligence (Sternberg and Grigorenko 2006). These four dimensions are metacognitive, cognitive, motivational and behavioral CQ. Metacognitive CQ refers to the processes people use to gain and understand knowledge. Cognitive CQ refers to the structure of their knowledge about other cultures. Motivational CQ is the mental ability to have control over one's energy for a specific task or situation. Finally, behavioral CQ refers to how people openly react and is more about what they do then how they think (Ang et al. 2007). CQ is generally measured with the 20-item Cultural Intelligence Scale (CQS), which was developed and validated by Ang et al. (2007).

CQ shares resemblance to, yet is different from emotional intelligence (EI) or intellectual capacity (Crowne 2009, 2013). Intellectual capacity is mostly measured by intelligence quotient (IQ) scores testing peoples raw basic processing functions and their ability to deal with complexity (Block and Kremen 1996). Given that intelligence is multifaceted, CQ can be seen as a type of intelligence. Furthermore, CQ is related to emotional intelligence (EI), 
which is most often defined as “the ability to monitor one's own and other s' emotions, to discriminate among them, and to use the information to guide one's thinking and actions" (Salovey and Mayer 1990, p.189). EI and CQ share the tendency to be susceptible to new ideas and behaviors, the capacity to think about one's own cognitions and being open to and capable of engaging in new behaviors (Crowne 2009). However, while EI pertains to other people's idiosyncratic emotions, CQ refers to particularities in people's emotions or behaviors that can be linked to their membership of cultural groups and - hence- can be generalized to all members of this group. CQ thus "picks up where emotional intelligence leaves off" (Earley and Mosakowski 2004, p. 1). Empirical evidence supports the idea that CQ and EI are distinct yet related, as their correlation varies around .30 (Crowne 2013).

The concept of CQ was developed to understand why some individuals are more effective than others in culturally diverse situations (Ang et al. 2007; Earley and Ang 2003). Some studies show that culturally intelligent associates positively with different performance outcomes such as job performance and adaptive performance ( $\mathrm{Ng}$ et al. 2012; Ott and Michailova 2016). This may be because CQ enables employees to understand and enact their role expectations with cultural sensitivity and cultural appropriateness (Ang et al. 2007). Employees with high levels of CQ use context, for example of a service encounter, to gain more knowledge about cultural features that may come into play. They are also very proficient in looking for additional cues and suspending judgment based on stereotypes (Triandis 2006). Employees with high levels of behavioral CQ are subsequently flexible in adapting their behaviors, both verbal and nonverbal, to meet the expectations of the other party from a different cultural background. This ultimately leads to a decrease in the number of misunderstandings in cross-cultural interactions. In short, highly CQ employees are aware of their culturally diverse environment and easily adapt their behaviors according to the situation (Ang et al. 2007). 
Whether the positive effects of CQ also hold for service recovery performance, is yet to be examined. However, given that customers with different cultural backgrounds have different recovery expectations (Orsingher et al. 2010; Patterson et al. 2006), and culturally intelligent employees are better able to adapt and respond to culture specific sensitivities and expectations (Ang et al. 2007), we propose that this may be the case such that culturally intelligent employees report higher levels of service recovery performance. Specifically, we hypothesize:

Hypothesis 1: Cultural intelligence is positively associated with service recovery performance.

\subsection{The mediating role of work engagement}

Although knowledge on the beneficial effects of CQ on performance is growing, the processes underlying these effects are less well-understood (Ott and Michailova 2016). To shed light on the process through which CQ relates to service recovery performance, we rely on the JD-R theory and the construct of work engagement in particular. Work engagement is defined as an active, positive work-related state of mind which is characterized by vigor (i.e. high levels of energy), dedication (i.e. feeling proud about one's work) and absorption (i.e. losing track of time when working) (Schaufeli et al. 2006). Following the JD-R theory, engagement may be a valuable candidate for mediation since personal resources, such as CQ, influence engagement positively ( $\mathrm{Ng}$ et al. 2012) and engagement is known as a predictor of performance (Demerouti et al. 2010).

Specifically, following the JD-R theory, we advance that the culturally diverse work environment may tap into high CQ employees' extrinsic and intrinsic motivation, and therefore increase work engagement: CQ likely leads to work engagement because it helps employees working in a culturally diverse environment to reach their goals (Locke and 
Latham 2002). Apart from being extrinsically motivating, CQ may also be intrinsically motivating as working in a culturally diverse environment furthermore enables employees with high CQ to use and develop their cultural knowledge, values, verbal and non-verbal inter-cultural behavior. This likely makes them feel competent and autonomous when interacting with cultural diverse customers, and adds to their experience of relatedness. Such feelings are known to result in high work engagement (Deci and Ryan 2000; Van den Broeck, et al. 2016).

Furthermore, various studies also show that work engagement relates positively to performance (Demerouti et al. 2010). One explanation for this engagement-performance link is that engaged workers have more mental and physical resources (Schaufeli et al. 2008). This means that people scoring high on work engagement experience are in good mental health, are sociable and experience many resources in their job environment, which ultimately results in better performance. Additionally, when employees feel vigorous, involved, and happy in the workplace -hence- engaged, it results in positive perceptions about the service climate, which increases employee performance (Salanova et al. 2005). The engagement-performance relationship has already been demonstrated in a service recovery context, with employee work engagement being positively associated with their recovery performance (Karatepe 2012; Kim and Oh 2012). Given the fact that high CQ employees are more likely to be engaged when interacting with culturally diverse customers, and engagement relates positively to service recovery performance, we propose the following hypothesis:

Hypothesis 2: Work engagement mediates the relationship between cultural intelligence and service recovery performance. 


\section{Methodology}

\subsection{Sample and procedure}

To test our hypothesis, we collected survey data among a sample of flight attendants of a Southeast Asian airline. The airline offers routes to Europe, Australia and Asia ${ }^{1}$. Only flight attendants serving customers on the long-haul international routes were allowed to participate in the survey, as they are most likely to interact with international customers on a day-to-day basis. Moreover, customers experiencing a service failure during a flight typically complain to the flight attendant, instead of complaining to the airline's headquarter later (Goodman 1999).

The research team had direct contacts with the human resources department of this particular airline, which was willing to distribute the online survey to their long-haul flight attendants via email. Participants were informed that the survey was part of academic research, and participation was voluntary. The survey was administered in English, as the airline requires high proficiency in English from its flight attendants. To make sure all questions are clearly understood, we pretested the surveys with five flight attendants. This resulted in only minor changes to the survey. The researchers guaranteed the flight attendants' anonymity, in several ways: The survey was sent out using the university's survey software, using the university logo and color schemes, to underscore the independent character of this research. The flight attendants were informed that the data were collected, processed and analyzed by a university researcher and that their supervisors and managers would receive aggregate insights only and would never receive or be able to track the flight attendants' individual responses. We sent a reminder to those flight attendants who did not complete the survey after one week.

\footnotetext{
${ }^{1}$ Because of confidentiality agreements, we do not disclose the name nor the country in which the airline is based.
} 
All 768 flight attendants and pursers serving on long-haul international flights were invited to participate in the survey via email. In total, 155 flight attendants provided usable answers to the survey, which is equivalent with a response rate of $20.2 \%$. The majority of the respondents were female (68.4\%). 16.1\% of the respondents was between 20 and 27 years old, $49.1 \%$ between 28 and 37 and $34.8 \%$ between 38 and 45 years old. The majority of the respondents $(75.5 \%)$ had more than 5 years of work experience in the company, $14.2 \%$ had a 3 to 5 years tenure and $10.3 \%$ had a 1 to 3 years tenure. These statistics reflect the population of flight attendants working for the airline.

\section{Measurement instrument}

We use established scales to measure all constructs. Table 2 provides an overview of all definitions of the constructs, while Table 3 provides an overview of all measurement items, their reliabilities, means, and standard deviations. In order to avoid common method bias, questions measuring service recovery performance, work engagement, job resources and cultural intelligence were separated throughout the questionnaire. In order to avoid order effects, which typically arise when researchers measure the independent variables before the mediating variables and before the dependent variables (Krosnick and Presser 2009), we first measured employees' service recovery performance, then work engagement, then job resources and finally cultural intelligence.

Table 2 and 3 here.

Cultural intelligence. CQ is measured using the 20-item seven-point Likert scale from Ang et al. (2007). The CQ scale is a second-order reflective construct (Thomas et al. 2015), including the four sub dimensions of CQ (metacognitive, cognitive, motivational and behavioral CQ) as first-order reflective constructs.

Work engagement. Work engagement is measured using the nine-item Utrecht Work Engagement Scale (UWES-9) of Schaufeli, Bakker and Salanova (2006). The UWES-9 on a 
seven-point Likert scale is a shorter version of the original Utrecht Work Engagement Scale, but has satisfactory psychometric properties. The UWES-9 scale is modeled as a secondorder reflective construct, with vigor (3 items), dedication (3 items), and absorption (3 items) as first-order reflective constructs.

Service recovery performance. Respondents rate their service recovery performance on a seven-point Likert scale using the scale adopted from Boshoff and Allen (2000). Ashill and Rod (2011) suggest that frontline employees "are in the best position to evaluate performance outcomes" (p. 1120). Self-rated performance ratings and performance ratings by others typically converge in case of non-managerial jobs (Conway and Huffcut 1997), and when the data is collected anonymously (Singh 2000). Hence, the focus on frontline employees and the use of an anonymous online survey justifies the use of self-rated performance measure.

Control variables. Considering that the job resources training, empowerment and rewards play a significant role in daily functioning and service recovery of employees (Van Vaerenbergh and Orsingher 2016), we also test whether CQ is related to service recovery performance above and beyond these variables by adding them as covariates in a later stage of the analysis. Training is referred to as educating the skills of employees to improve customer interactions and increase service quality (Babakus et al. 2003). Empowerment refers to employees' feelings of authority and autonomy to make decisions and commitments regarding customer complaints, while rewards refer to financial and non-financial compensations for good customer complaint handling (Babakus et al. 2003). Respondents rated their level of training, empowerment and rewards using scales adopted from Boshoff and Allen (2000). 


\section{Results}

\subsection{Psychometric properties}

Before testing the hypotheses, we assessed the constructs' psychometric properties. Construct reliability is achieved when all factor loadings are larger than 0.60 . Convergent validity is achieved if all composite reliability $(\mathrm{CR})$ values exceed 0.70 and all average variance extracted values (AVE) exceed 0.50. Discriminant validity is achieved when the AVE estimate for every construct exceeds the squared correlation between the two constructs (Bagozzi and Yi 1988; Fornell and Larcker 1981).

After the initial run, two items of the service recovery performance measure did not meet the construct validity threshold (i.e. factor loadings $>0.60$ ). As shown in Table 3 and 4, after excluding both measurement items, all constructs show satisfactory levels of construct validity (all factor loadings $>.60$ ), convergent validity (all CRs $>.70$ and all AVEs $>.50$ ) and discriminant validity (all AVEs $>$ squared correlations between constructs). Despite that the other fit indices (comparative fit index $[\mathrm{CFI}]=.81$ and Tucker-Lewis index $[\mathrm{TLI}]=.80$ ) are not satisfactory, the measurement model therefore seems appropriate.

\section{Table 4 here.}

\subsection{Hypotheses testing}

We test the first hypothesis using a linear regression model and use the PROCESS analysis (model 4; Hayes 2013) to test the second, mediation hypothesis. Parameter estimates were obtained using a bootstrapping procedure with 5,000 resamples.

The model with only CQ as independent variable explains $17.3 \%$ of the variance in service recovery performance. Adding engagement as a mediator increases the explained variance in service recovery performance to $31.9 \%$. Table 5 lists the results of both models. The findings show that the relationship between CQ and frontline employees' service recovery performance is positive $(\beta=0.38, p<.001)$, supporting hypothesis 1 . The second 
hypothesis proposes that this relationship is mediated by work engagement. CQ has a positive association with work engagement $(\beta=0.22, p=0.03)$, which in turn has a positive association with service recovery performance $(\beta=0.33, p<0.001)$. The indirect effect of CQ on service recovery performance through work engagement appears to be positive $(\beta=$ 0.07 ) and the confidence intervals of the indirect effect do not include zero [0.004, 0.172], indicating a significant indirect effect. These findings support hypothesis 2 .

\subsection{Robustness tests}

In order to test the robustness and significance of our results, we examine the relationship of CQ with service recovery while controlling for training, empowerment, and rewards. This allows us to assess whether CQ explains variance in the service recovery performance measure above and beyond more traditional drivers of recovery performance. Moreover, we conducted a relative weights analysis (Johnson 2000) to assess the relative weight of CQ's association with service recovery performance vis-à-vis training, empowerment, and rewards. The model with four independent variables explains $21.8 \%$ of the variance in service recovery performance. Table 6 lists the results. The results show that even when controlling for more traditional drivers of recovery performance, CQ is positively associated with service recovery performance $(\beta=0.32, p<.001)$. Training $(\beta=0.20, p<$ .015) relates also positively to service recovery performance, while empowerment $(\beta=0.09$, $p<.782)$ and rewards $(\beta=0.09, p<.100)$ are unrelated to service recovery performance. CQ contributes most to the explained variance in service recovery performance $(44.5 \%)$, followed by training (25.6\%), rewards (17.4\%) and empowerment (12.5\%).

In order to fully understand the relative effects of these four independent variables, we test whether the slopes of the independent variables are significantly different from each other (see Gujarati 2003). The results show that CQ is more strongly related to SRP than empowerment $(\mathrm{t}(151)=2.29, \mathrm{p}=.023)$ or rewards $(\mathrm{t}(151)=2.48, \mathrm{p}=.014)$, but not compared 
to training $(\mathrm{t}(151)=1.15, \mathrm{p}=.250$; Johnson 2000; Gujarati 2003). These findings suggest that CQ and training have a similar effect on service recovery performance, while CQ has a significantly stronger impact on service recovery performance than empowerment or rewards.

Finally, we calculated the statistical power of our hypotheses tests. Statistical power refers to the probability of correctly rejecting a false null hypothesis. The statistical power analysis can help determine whether our sample of 155 flight attendants is sufficient to derive meaningful conclusions. We used $\mathrm{G}^{*}$ power to calculate the statistical power. The effect size, the alpha level (.05) and the number of respondents (Faul et al. 2009) serve as input. We proceed in two ways. First, we calculate the statistical power of the overall regression model (adjusted $\mathrm{R}^{2}=.319$ ). The analysis reveals a statistical power larger than .999. Second, we compute the statistical power for the three correlations among the focal variables. The results reveal a statistical power larger than .999 for the relationship between CQ and service recovery performance, a statistical power larger than .999 for the relationship between engagement and service recovery performance, and a statistical power of .88 for the relationship between CQ and engagement. The statistical power for all the relationships and the overall model largely exceed the recommended .80 threshold, suggesting that we can derive meaningful findings from the analyses.

\section{Discussion}

The purpose of this study was twofold. First, we aimed to examine whether cultural intelligence (CQ) is a viable personal resource for frontline employees' service recovery performance in a culturally diverse context. Second, we aimed to test whether this relationship can be explained by work engagement. This study broadens our understanding of the usefulness of CQ in an international market work context and contributes to the literature in the following ways. 
First, with the current study, we broaden the scope of research on intercultural service recovery encounters. While the literature predominantly focuses on understanding cultural differences in the effectiveness of organizational responses to service failures, the current study approaches these encounters from an employee perspective. Interestingly, our findings reveal that CQ has a relationship with service recovery performance above and beyond more traditional antecedents such as training, empowerment, and rewards. In terms of strength of relationships, CQ has a stronger relationship with service recovery performance than empowerment or rewards, and an equally strong relationship with service recovery performance as employee training. The findings support Alshaibani and Bakir's (2016) proposition that CQ is positively related to frontline service employees' performance. Taking a broader perspective, they also provide empirical support for Van Vaerenbergh and Orsingher's (2016) notion that researchers need to direct their attention to understanding the role of personal resources in a service recovery context.

From a theoretical point of view, this study adds to the literature on JD-R theory. This literature predominantly focused on job resources and demands, but personal resources deservedly gain more attention. The results of this study support the movement towards a focus on personal resources, as it evidences that personal resources such as CQ can be as and even more- important than job resources (Van den Broeck et al. 2013). More specifically, the job resource training is as important as the personal resource CQ, but both are more important than the job resources empowerment and rewards.

By supporting a relationship between CQ and service recovery performance, this study also contributes to a better understanding of the CQ concept. To date, researchers typically examined how CQ influences leaders and/or expatriates' adjustment and adaptation to a new culture, or increases their performance in a different culture (Huff et al. 2014; Lee and Sukoco 2010; Malek and Budhwar 2013). Recent review papers strongly questioned the 
applicability of CQ (Ng et al. 2012), especially for employees lower in rank or nonexpatriates (Ng et al. 2012; Ott and Michailova 2016). Furthermore, they wondered whether CQ is related to "other challenges associated with international assignments" (Ott and Michailova 2016, p. 14). Dealing with customer complaints coming from customers with diverse cultural backgrounds represents such a challenge. Our findings reveal an association between $\mathrm{CQ}$ and performance at a lower employee level and in a non-expatriate context $(\mathrm{Ng}$ et al. 2012). Hence, we show that CQ may have broader applications than assumed in extant CQ literature. This study uses a sample of flight attendants in an emerging market. They are residing in their home country, but have to deal with an influx of international customers. We expect that, due to globalization, fewer travel restrictions and open economies, frontline employees will have to deal with international customers more often in the future, which represents the relevance of CQ from the point of view of this study.

Moreover, the paper aimed to unravel the process through which CQ relates to service recovery performance by relying on the JD-R theory and research on work engagement. The results support an indirect effect of CQ on service recovery performance through work engagement. This implies that culturally intelligent employees provide better service recovery, because they are more engaged. With these findings, we address Ott and Michaelova's (2016) call for a theory-based explanation for why CQ may affect performance. Moreover, we provide empirical support for the integrative framework of Van Vaerenbergh and Orsingher's (2016), which posits that personal resources influence service recovery performance through job engagement.

\subsection{Managerial implications}

This research assists researchers and managers to think differently about the possibilities of culturally intelligent employees and the advantage of cultural intelligence for the employee engagement and organizations' service recovery. It shows that CQ is equally applicable to 
lower level employees dealing with international customers, and is not restricted to expatriates and global leaders. Hence, managers need to recruit and select employees who have potential to develop good cultural intelligence for all frontline positions dealing with customers from diverse background. As international experience and exposure to different cultures increases CQ (Ott and Michailova 2016), organizations hiring new employees or willing to increase the $\mathrm{CQ}$ of current employees may consider putting these recruits into an international training program. These employees may live and work in another country for a certain period of time or work in culturally diverse teams, before starting to interact with culturally diverse customers.

We believe that CQ is relevant in both mature and emerging markets. Nowadays almost all service employees have to serve culturally diverse customers. Due to globalization, all cities over the world are inhabited by people from different cultural backgrounds. A bus driver, bartender or any other service employee working in a city needs to be able to address the needs of a culturally diverse customers. Industry reports indicate that service employees in emerging markets struggle with their service recovery activities (Accenture 2008, 2013), an issue that becomes even more challenging when considering the increased number of interactions with culturally diverse customers. In order to provide satisfactory service recovery to these customers, organizations may try to foster CQ among their employees.

\subsection{Limitations and suggestions for future research}

As with any study, the current research carries some limitations that may serve as fruitful avenues for future research. First, the current study focuses on flight attendants of a single airline. As we rely on well-established constructs and sound theory that have been used in research around the globe (Van den Broeck et al. 2013; Ng et al. 2012), we are confident that the results hold beyond this specific sample. However, future research may aim to replicate 
the current findings and investigate CQ in multiple airlines or other settings in which CQ is especially relevant. A possible avenue for future research could be to test whether the relationship of CQ with service recovery performance differs among flight attendants serving customers on long-haul flights and flight attendants mainly serving customers on shorter flights, (i.e. flights within a country or between countries with a similar culture). This may give insights into the breadth of application of the CQ construct. Additionally, other variables might mediate the relationship between CQ and service recovery performance, such as for example burn-out. Future research could investigate if employees scoring low on CQ might exhaust their mental resources, leaving them depleted and burned out (Maslach, 1986). Burnout is typically negatively related to service recovery performance (Van Vaerenbergh and Orsingher 2016).

Second this research relies on a self-rated service recovery performance measure. This is in line with previous research (e.g. Ashill and Rod 2011; Boshoff and Allen 2000). It is also relevant to focus on self-rated data since CQ and engagement are personal characteristics that are difficult to observe objectively by peers or customers. Future research may however want to replicate the current findings using a manager-rated and/or customer-rated service recovery performance measure. Third, the data of this research is cross-sectional. Although such data does not allow to draw causal relationships, this is not necessarily a problem as our model aligns with recent longitudinal studies showing that $\mathrm{CQ}$ relates to performance, rather than the other way around (Ang et al. 2007).

In sum, the results of this study provide empirical support for the positive direct and indirect effect of CQ on service recovery performance. This study is a first step toward enhancing our understanding on the direct effect of personal resources in de JD-R theory and the comparison of $\mathrm{CQ}$ as a personal resource to the most established job resources in service recovery performance literature. 


\section{References}

Accenture (2008) Customer service quality falling short of rising expectations across the globe, Accenture study finds. https://newsroom.accenture.com/industries/consumergoods--services/customer-service-quality-falling-short-rising-expectations-across-globeaccenture-study-finds.htm (Accessed September 20, 2016)

Accenture (2013). Accenture 2013 Global Consumer Pulse Survey: Global \& U.S. Key Findings. https://www.accenture.com/t20150523T052453_w_ _ usen/_acnmedia/Accenture/ConversionAssets/DotCom/Documents/Global/PDF/Strategy_3/Accenture-Global-Consumer-PulseResearch-Study-2013-Key-Findings.pdf (Accessed September 20, 2016)

Ackerman (1996) A theory of adult intellectual development: Process, personality, interests, and knowledge. Intelligence 22: 227-257.

Alshaibani E, Bakir A (2016) A reading in cross-cultural service encounter: Exploring the relationship between cultural intelligence, employee performance and service quality. Tour Hosp Res 17(3): 249-263

Ang S, Van Dyne L, Koh C, Ng K Y, Templer K J, Tay C, Chandrasekar N A (2007) Cultural intelligence: Its measurement and effects on cultural judgment and decision making, cultural adaptation and task performance. Manage Organ Rev 3(3): 335-371

Ashill N J, Rod M (2011) Burnout process in non-clinical health service encounters. J Bus Res 64(10): 1116-1127

Babakus E, Yavas U, Karatepe O M, Avci T (2003) The effect of management commitment to service quality on employees' affective and performance outcomes. J Acad Market Sci 31(3): 272-286

Bagozzi R P, Yi Y (1988) On the evaluation of structural equation models. J Acad Market Sci 16: $74-97$ 
Bakker A B, Demerouti E (2007) The job demands-resources model: State of the art. J Manage Psychol 22(3): 309-328

Bakker A B, Demerouti E, Sanz-Vergel A I (2014) Burnout and work engagement: The JD-R approach. Annu Rev Organ Psych 1(1): 389-411

Block J, Kremen A M (1996) IQ and ego-resiliency: conceptual and empirical connections and separateness. J Pers Soc Psych 70(2): 349-361.

Boshoff C, Allen J (2000) The influence of selected antecedents on frontline staff's perceptions of service recovery performance. Int J Serv Ind Manag 11(1): 63-90

Ceci (1996) On intelligence: A bioecological treatise on intellectual development. Harvard University Press, Cambridge

Choi H C, Kim T, Lee G, Lee S K (2014) Testing the stressor-strain-outcome model of customer-related social stressors in predicting emotional exhaustion, customer orientation, and service recovery performance. Int J Hosp Manag 36(1): 272-285

Conway J M, Huffcut A I (1997) Psychometric properties of multisource performance ratings: A meta-analysis of subordinate, supervisor, peer, and self-ratings. Hum Perform 10(4): $331-360$

Crowne K A (2009) The relationships among social intelligence, emotional intelligence and cultural intelligence. Org Manag J 6(3): 148-163

Crowne K A (2013) Cultural exposure, emotional intelligence, and cultural intelligence: An exploratory study. Int J Cross Cult Manag 13(1): 5-22

Deci E L, Ryan R M (2000) The "what" and "why" of goal pursuits: Human needs and the selfdetermination of behavior. Psychol Inq 11(4): 227-268

Demerouti E, Cropanzano R, Bakker A B, Leiter M P (2010) From thought to action: Employee work engagement and job performance. In : Work engagement: A handbook of essential theory and research. Psychology Press, New York, pp 147-163 
Earley P C, Ang S (2003) Cultural intelligence: Individual interactions across cultures. Stanford University Press, Stanford C.A.

Earley P C, Mosakowski E (2004) Cultural intelligence. Harvard Bus Rev 82(10): 139-146

Faul F, Erdfelder E, Buchner A, Lang A G (2009) Statistical power analyses using G* Power 3.1: Tests for correlation and regression analyses. Behav Res Methods 41(4): 1149-1160

Fornell C, Larcker D F (1981) Evaluating structural equation models with unobservable variables and measurement error. J Marketing Res 28: 39-50

Gelbrich K, Roschk H (2011) A meta-analysis of organizational complaint handling and customer responses. J Serv Res 14(1): 24-43

Goodman J (1999) Basic facts on customer complaint behavior and the impact of service on the bottom line. Comp Adv, 9(1), 1-5

Gujarati D (2003) Basic Econometrics 4th ed. McGraw Hill, New York

Hayes A F (2013) Introduction to mediation, moderation, and conditional process analysis: A regression-based approach. Guilford Press, New York

Hazée S, Van Vaerenbergh Y, Armirotto V (2017) Co-creating service recovery after service failure: The role of brand equity. J Bus Res 74(1), 101-109

Hobfoll S E (1989) Conservation of resources: A new attempt at conceptualizing stress. Am Psychol 44(3): 513-524

Hobfoll S E, Johnson R J, Ennis N, Jackson A P (2003) Resource loss, resource gain, and emotional outcomes among inner city women. J Pers Soc Psychol 84(3): 632-643

Huff K C, Song P, Gresch E B (2014) Cultural intelligence, personality, and cross-cultural adjustment: A study of expatriates in Japan. Int J Intercult Rel 38: 151-157

Hui M K, Au K (2001) Justice perceptions of complaint handling: A cross-cultural comparison between PRC and Canadian customers. J Bus Res 52(2): 161-173 
Johnson J W (2000) A heuristic method for estimating the relative weight of predictor variables in multiple regression. Multivar Behav Res 35(1): 1-19

Judge T A, Locke E A, Durham C C (1997) The dispositional causes of job satisfaction: A core evaluations approach. Res Organ Behav 19: 151-188

Karatepe O M (2012) Job resources, work engagement, and hotel employee outcomes: A timelagged analysis. Econ Res 35(4): 1127-1140

Kim S M, Oh J Y (2012) Employee emotional response toward healthcare organization's service recovery efforts and its influences on service recovery performance. Serv Bus 6(3): 297-321

Kotabe M, Kothari T (2016) Emerging market multinational companies' evolutionary paths to building a competitive advantage from emerging markets to developed countries. J World Bus. doi: 10.1016/j.jwb.2016.07.010

Krosnick, J A, Presser, S (2009) Question and questionnaire design. In : Wright J D, Marsden P V (eds.). Handbook of Survey Research $2^{\text {nd }}$ edition. Elsevier, San Diego, CA

Lee J H, Kim M S, Jeon A (2013) The effects of emotional intelligence on service recovery and organizational loyalty: A case of flight attendants of South Korean Airlines. Serv Bus 7(4): 665-686

Lee L Y, Sukoco B M (2010) The effects of cultural intelligence on expatriate performance: The moderating effects of international experience. Int J Hum Resour Man 21(7): 963-981

Liao H (2007) Do it right this time: the role of employee service recovery performance in customer-perceived justice and customer loyalty after service failures. J Appl Psychol 92(2): $475-489$

Lin Y, Chen A S, Song Y (2012) Does your intelligence help to survive in a foreign jungle? The effects of cultural intelligence and emotional intelligence on cross-cultural adjustment. Int J Intercult Rel 36(4): 541-552 
Locke E A, Latham G P (2002) Building a practically useful theory of goal setting and task motivation: A 35-year odyssey. Am Psychol 57(9): 705-717

Malek M A, Budhwar P (2013) Cultural intelligence as a predictor of expatriate adjustment and performance in Malaysia. J World Bus 48: 222-231

Maslach C (1986) Stress, burnout and workaholism. In : Killberg R R, Nathan P E, Thoreson R W (ed) Professionals in distress: Issues, syndromes and solutions in psychology. American Psychological Association, Washington D.C., U.S., pp 53-73

Ng K Y, Van Dyne L, Ang S, Ryan A M (2012) Cultural intelligence: A review, reflections, and recommendations for future research. In : Ryn A M, Leong F T L, Oswald F L (ed) Conducting multinational research: Applying organizational psychology in the workplace. American Psychological Association, Washington D.C., U.S., pp 29-58

Orsingher C, Valentini S, de Angelis M (2010) A meta-analysis of satisfaction with complaint handling in services. J Acad Market Sci 38(2): 169-186

Ott D L, Michailova S (2016) Cultural intelligence: A review and new research avenues. Int J Manag Rev. doi: 10.1111/ijmr.12118

Patterson P G, Cowley E, Prasongsukarn K (2006) Service failure recovery: the moderating impact of individual-level cultural value orientation on perceptions of justice. Int J Res Mark 23(3): 263-277

Rizal H, Feng D J F, Chang H H (2016) The role of ethnicity in domestic intercultural service encounters. Serv Bus 10(2): 263-282

Salanova M, Agut S, Peiró J M (2005) Linking organizational resources and work engagement to employee performance and customer loyalty: the mediation of service climate. J Appl Psychol, 90(6): 1217-1227

Salovey P, Mayer J D (1990) Emotional intelligence. Imag Cogn Person 9: 185-211. 
Schaufeli W B, Bakker A B (2004) Job demands, job resources, and their relationship with burnout and engagement: A multi-sample study. J Organ Behav 25: 293-315

Schaufeli W B, Bakker A B, Salanova M (2006) The measurement of work engagement with a short questionnaire a cross-national study. Educ Psychol Meas 66(4): 701-716

Schaufeli W B, Taris T W, Van Rhenen W (2008) Workaholism, burnout, and work engagement: three of a kind or three different kinds of employee well-being? Appl Psychol 57(2): 173-203

Scheier M F, Carver C S (1992) Effects of optimism on psychological and physical well-being: Theoretical overview and empirical update. Cognitive Ther Res 16(2): 201-228

Sengupta S, Ray D, Trendel O, Van Vaerenbergh Y (2018) The effects of apologies for service failures in the global online retail. Int J Elec Commer 22(3): 419-445.

Sharma P, Tam J, Kim N (2009) Demystifying intercultural service encounters: Toward a comprehensive conceptual framework. J Serv Res 12(2): 227-242

Sharma P, Tam J, Kim N (2012) Intercultural service encounters (ICSE): An extended framework and empirical validation. J Serv Mark 26(7): 521-534

Singh J (2000) Performance productivity and quality of frontline employees in service organizations. J Marketing 64(2): 15-34

Smith J S, Karwan K R, Markland R E (2009) An empirical examination of the structural dimensions of the service recovery system. Decision Sci 40(1): 165-186

Sternberg, Detterman (1986) What is intelligence?: Contemporary viewpoints on its nature and definition. Ablex, Norwood N.J.

Sternberg, Grigorenko (2006) Cultural intelligence and successful intelligence. Group Organ Man 31: 27-39 
The Travel and Tourism competitiveness report 2015 http://reports.weforum.org/travel-andtourism-competitiveness-report-2015/economies/" \1 "economy=VNM (Accessed August 11, 2016)

Thomas D C, Liao Y, Aycan Z, Cerdin J L, Pekerti A A, Ravlin E C, Stahl G K, Lazarova M B, Fock H, Arli D, Moeller M, Okimoto T G, van de Vijver F (2015) Cultural intelligence: A theory-based, short form measure. J Int Bus Stud 46(9): 1099-1118

Triandis H C (2006) Cultural intelligence in organizations. Group Organ Manage 31(1): 20-26 Van den Broeck A, Ferris D L, Chang C H, Rosen C C (2016) A review of self-determination theory's basic psychological needs at work. J Manage 42(5): 1195-1229

Van den Broeck A, Van Ruysseveldt J, Vanbelle E, De Witte H (2013) The job demandsresources model: overview and suggestions for future research. In : Bakker A B (ed) Advances in positive organizational psychology, volume 1. Emerald Group Publishing Limited, U.K., pp 83-105

Van Vaerenbergh Y, Orsingher C (2016) Service recovery: An integrative framework and research agenda. Acad Manage Perspect 30(3): 328-346

Wang C Y, Mattila A S (2010) A grounded theory model of service providers' stress, emotion, and coping during intercultural service encounters. Manag Serv Qual 20(4): 328-342

Xanthopoulou D, Bakker A B, Demerouti E, Schaufeli W B (2007) The role of personal resources in the job demands-resources model. Int J Stress Manage 14(2): 121-141 


\begin{tabular}{|c|c|c|c|}
\hline \multicolumn{2}{|c|}{ Type of service recovery encounter } & & \\
\hline 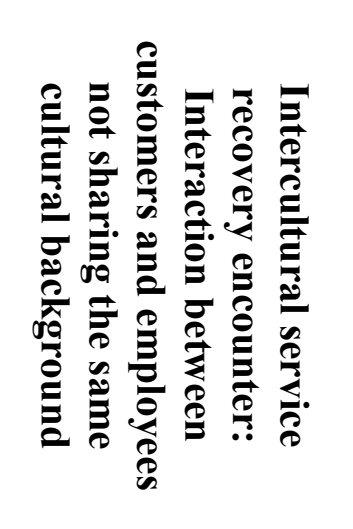 & 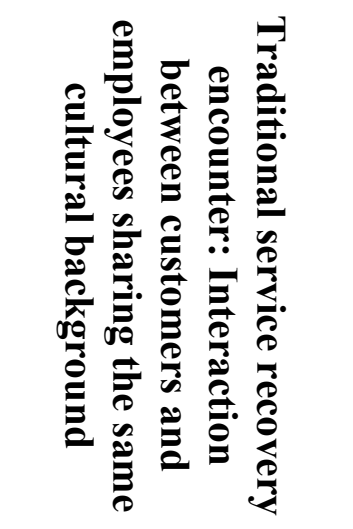 & & \\
\hline 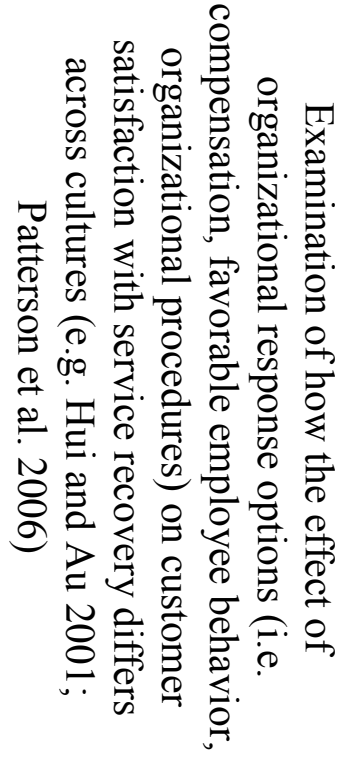 & 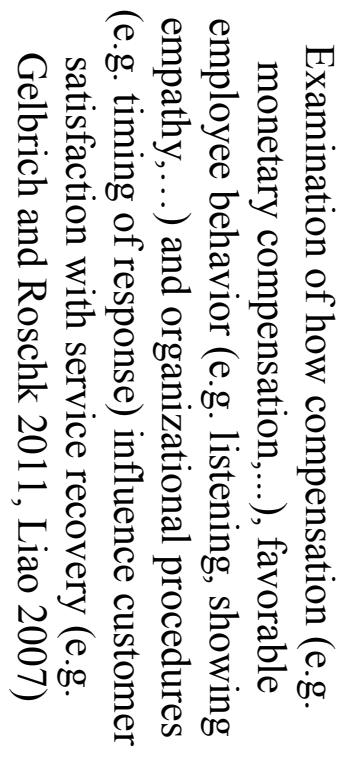 & 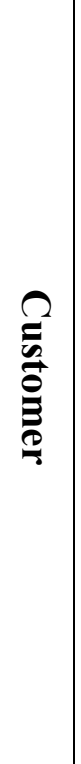 & $\begin{array}{c}e \\
e\end{array}$ \\
\hline 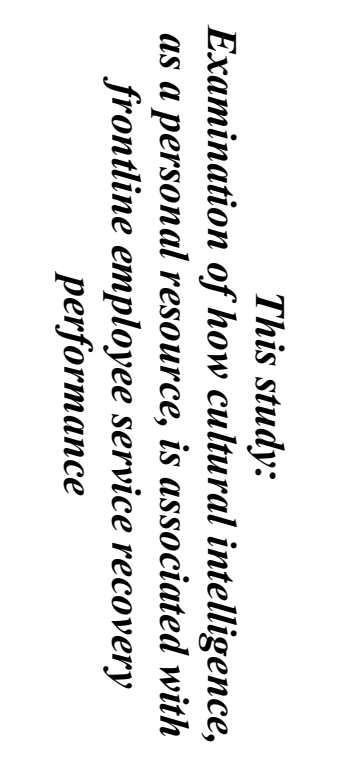 & 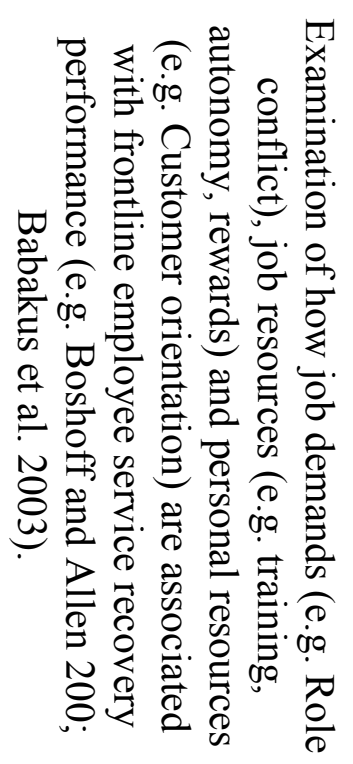 & 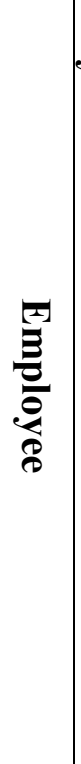 & \\
\hline
\end{tabular}


Table 2: Definition of the constructs

Concept

Cultural intelligence (CQ)

Metacognitive intelligence

Cognitive intelligence

Motivational intelligence

Behavioral intelligence

Service recovery performance (SRP)

Work engagement
Definition

Reference

"An individual's capability to function and manage culturally diverse settings effectively, [...] targeted at situations involving cross-cultural interactions arising from differences in race, ethnicity, and nationality" (Ang et al. 2007, p. 336).

Ang et al. (2007), p. 336-337

"Control of cognition: the processes individuals use to acquire and understand knowledge."

"Knowledge structures, consistent with Ackerman's (1996) intelligence-as-knowledge concept, which argues for the importance of knowledge as part of the intellect."

"The mental capacity to direct and sustain energy on a particular task or situation and recognize that motivational capabilities are critical to 'real world' problem solving (Ceci 1996)."

"Outward manifestations or overt actions: what people do rather than what they think (Sternberg 1986, p. 6)."

The effectiveness of employees in satisfying complaining customers

An active, positive work-related state of mind which is characterized by vigor (i.e. high levels of energy), dedication (i.e. feeling proud about one's work) and absorption (i.e. losing track of time when working).
Schaufeli et

Boshoff and Allen (2000)

al. (2006) 
Considering all the things I do, I handle dissatisfied customers quite well

No customer I deal with leaves with problems unresolved

Satisfying complaining customers is a great thrill to me*

Complaining customers I have dealt with in the past are among today's most loyal customers*

Work engagement $(\mathrm{CR}=0.98, \mathrm{AVE}=\mathbf{0 . 9 3})$

Vigor $(C R=0.98, A V E=0.95)$

At my work, I feel bursting with energy

$\begin{array}{lll}2.74 & 1.19 & 0.91\end{array}$

At my job, I feel strong and vigorous

$2.89 \quad 1.23$

0.90

I am enthusiastic about my job

$2.45 \quad 0.96$

0.77

Dedication $(C R=0.96, A V E=0.88)$

My job inspires me

$2.64 \quad 1.03$

0.79

When I get up in the morning, I feel like going to work

$3.21 \quad 1.21$

0.69

I feel happy when I am working intensely

$\begin{array}{lll}2.46 & 1.13 & 0.78\end{array}$

Absorption $(C R=0.94, A V E=0.85)$

I am proud of the work that I do

$\begin{array}{lll}1.90 & 0.88 & 0.67\end{array}$

I am immersed in my work

I get carried away when I am working

$2.81 \quad 1.08$

0.85

Cultural intelligence $(C R=0.94, A V E=0.81)$

Meta-cognitive cultural intelligence ( $C R=0.98, A V E=0.92$ )

I am conscious of the cultural knowledge I use when interacting with people with different cultural background

$2.14 \quad 0.79 \quad 0.86$

I adjust my cultural knowledge as I interact with people from a culture that is unfamiliar to me

$2.35 \quad 0.92$

0.71

I am conscious of the cultural knowledge I apply to cross-cultural interactions

$2.23 \quad 0.78 \quad 0.96$

I check the accuracy of my cultural knowledge as I interact with people from different cultures

Cognitive cultural intelligence $(C R=0.98, A V E=0.88)$

I know the legal and economic systems of other cultures

I know the rules (e.g., vocabulary, grammar) of other languages

I know the cultural values and religious beliefs of other cultures

I know the marriage systems of other cultures

I know the arts and crafts of other cultures

I know the rules for expressing nonverbal behaviors in other cultures

Motivational cultural intelligence $(C R=0.96, A V E=0.82)$

I enjoy interacting with people from different cultures

I am confident that I can socialize with locals in a culture that is unfamiliar to me

I am sure I can deal with the stresses of adjusting to a culture that is new to me

I enjoy living in cultures that are unfamiliar to me

I am confident that I can get accustomed to the shopping conditions in a different culture

$\begin{array}{lll}2.43 & 0.87 & 0.75\end{array}$

$\begin{array}{lll}3.18 & 1.16 & 0.74\end{array}$

$\begin{array}{lll}3.43 & 1.15 & 0.67\end{array}$

$\begin{array}{lll}3.07 & 1.14 & 0.84\end{array}$

$\begin{array}{lll}3.45 & 1.15 & 0.83\end{array}$

$\begin{array}{lll}3.54 & 1.08 & 0.84\end{array}$

$\begin{array}{lll}3.28 & 1.06 & 0.87\end{array}$

$\begin{array}{lll}2.34 & 0.91 \quad 0.68\end{array}$

$\begin{array}{lll}2.63 & 0.95 & 0.69\end{array}$

Behavioral cultural intelligence $(C R=0.99, A V E=0.93)$

I change my verbal behavior (e.g., accent, tone) when a cross-cultural interaction requires it 
I vary the rate of my speaking when a cross-cultural situation requires it $\begin{array}{lll}2.66 & 0.98 & 0.90\end{array}$ $\begin{array}{llll}\text { I change my nonverbal behavior when a cross-cultural situation requires } & 2.59 & 0.93 & 0.91\end{array}$ I alter my facial expressions when a cross-cultural interaction requires

$\begin{array}{lll}2.61 & 0.97 \quad 0.86\end{array}$

Notes: * item dropped during measure purification process. $\mathrm{M}=$ Mean, $\mathrm{SD}=$ Standard Deviation, $\mathrm{CR}=$ Composite reliability, $\mathrm{AVE}=$ Average Variance Extracted, items are measured using a seven-point Likert scale ranging from 1 (totally agree) to 7 (totally disagree). 
Table 3 (continued)

\section{Scale items}

Training $(\mathrm{CR}=0.97, \mathrm{AVE}=\mathbf{0 . 8 5})$

Employees of our company receive extensive customer service training before they come into contact with customers.

Employees of our company receive continued training to provide good service.

Employees of our company receive training on how to serve customers better.

Employees of our company are trained to deal with customer complaints.

Employees of our company receive training on dealing with customer problems.

Employees of our company receive training on how to deal with complaining customers. with complaining customers.

\section{Empowerment $(\mathrm{CR}=\mathbf{0 . 9 5}, \mathrm{AVE}=\mathbf{0 . 7 8})$}

I am allowed to do almost anything to solve customer problems.

I am empowered to solve customer problems.

I am encouraged to handle customer problems by myself.

I do not have to get management's approval before I handle customer problems.

I have control over how I solve customer problems.

Rewards $(C R=0.96, A V E=0.82)$

If I improve the level of service I offer customers, I will be rewarded. I am rewarded for satisfying complaining customers.

The rewards I receive are based on customer evaluations of service. Employees in this company are rewarded for serving customers well. Employees of this company are rewarded for dealing effectively with customer problems.
Factor

M SD loading

$\begin{array}{lll}1.85 & 0.80 & 0.64\end{array}$

$\begin{array}{lll}1.99 & 0.81 & 0.77\end{array}$

$\begin{array}{lll}1.85 & 0.74 & 0.79\end{array}$

$\begin{array}{lll}1.98 & 0.80 & 0.94\end{array}$

$\begin{array}{lll}2.03 & 0.82 & 0.93\end{array}$

$\begin{array}{lll}2.04 & 0.78 & 0.89\end{array}$

$\begin{array}{lll}3.08 & 1.27 & 0.61\end{array}$

$\begin{array}{lll}2.86 & 1.36 & 0.61\end{array}$

$\begin{array}{lll}3.72 & 1.60 & 0.89\end{array}$

$\begin{array}{lll}3.83 & 1.59 & 0.96\end{array}$

$\begin{array}{lll}3.12 & 1.35 & 0.84\end{array}$

$\begin{array}{lll}3.46 & 1.30 & 0.69\end{array}$

$\begin{array}{lll}2.86 & 1.27 & 0.70\end{array}$

$\begin{array}{lll}2.75 & 1.41 & 0.67\end{array}$

$\begin{array}{lll}2.90 & 1.39 & 0.72\end{array}$

$\begin{array}{lll}3.30 & 1.44 & 0.65\end{array}$

Notes: * item dropped during measure purification process. $\mathrm{M}=$ Mean, $\mathrm{SD}=$ Standard Deviation, $\mathrm{CR}=$ Composite reliability, $\mathrm{AVE}=$ Average Variance Extracted, items are measured using a seven-point Likert scale ranging from 1 (totally agree) to 7 (totally disagree). 
Table 4: Means, standard deviations and correlations $(\mathrm{N}=155)$

\section{Correlation}

\begin{tabular}{|c|c|c|c|c|c|c|c|c|c|}
\hline \multirow[b]{2}{*}{ Variables } & \multirow[b]{2}{*}{ M } & \multirow[b]{2}{*}{ SD } & \multirow[b]{2}{*}{$\mathbf{C R}$} & & \multirow[b]{2}{*}{4} & \multirow[b]{2}{*}{5} & \multirow[b]{2}{*}{6} \\
\hline & & & & 1 & 2 & 3 & & & \\
\hline 1. SRP & 2.65 & 0.85 & 0.96 & 0.88 & & & & & \\
\hline 2. CQ & 2.79 & 0.66 & 0.94 & 0.56 & 0.81 & & & & \\
\hline 3. Work engagement & 2.73 & 0.71 & 0.98 & 0.51 & 0.22 & 0.93 & & & \\
\hline 4. Training & 1.96 & 0.69 & 0.97 & 0.35 & 0.35 & 0.36 & 0.85 & & \\
\hline 5. Empowerment & 3.05 & 1.14 & 0.95 & 0.37 & 0.32 & 0.08 & 0.32 & 0.78 & \\
\hline 6. Reward & 3.32 & 1.09 & 0.96 & 0.28 & 0.45 & 0.26 & 0.38 & 0.49 & 0.82 \\
\hline
\end{tabular}

Notes: $\mathrm{M}=$ Mean, $\mathrm{SD}=$ Standard Deviation, $\mathrm{CR}=$ Composite Reliability, $\mathrm{SRP}=$ Service Recovery Performance, $\mathrm{CQ}=$ Cultural Intelligence, the diagonals (in bold) represent the average variance extracted, the other entries represent the correlations 


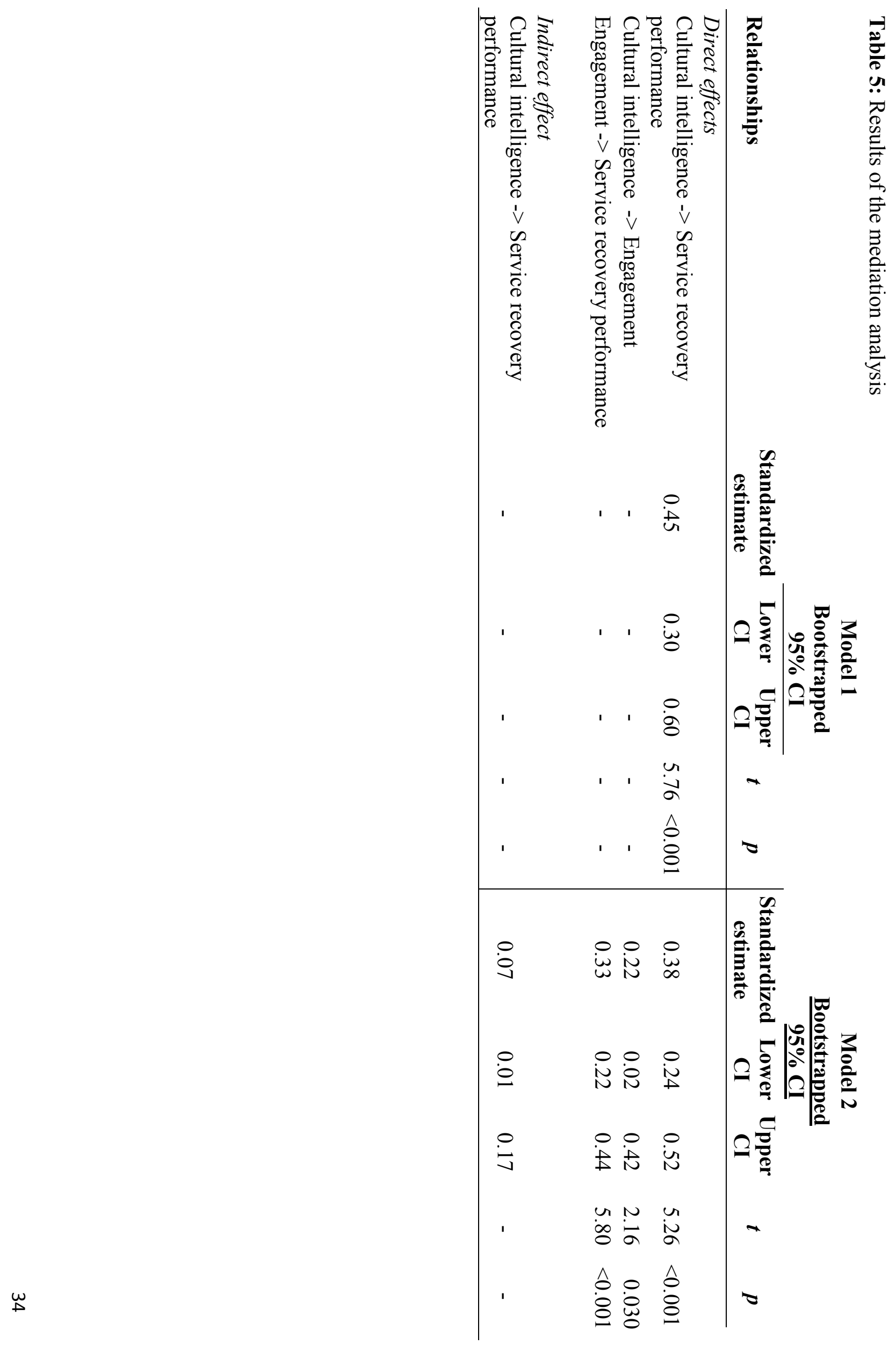




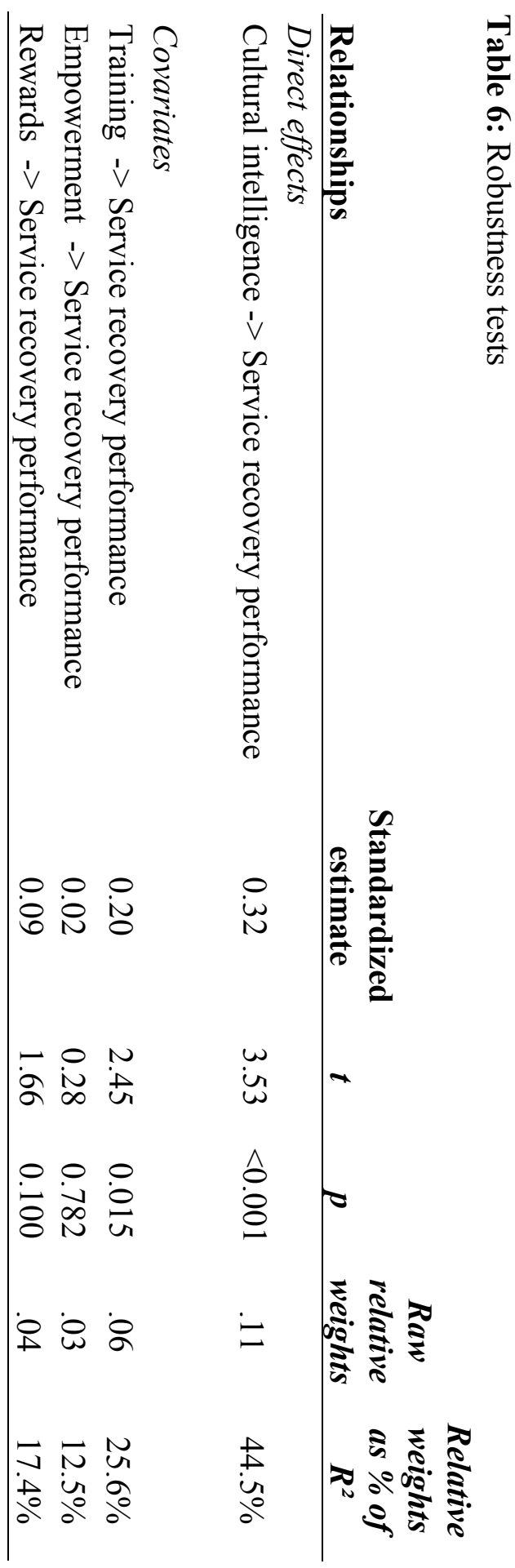

